\title{
Students’ Perceptions of the Effect of Flipping Online Classes Using a Synchronous Interactive Online Tool
}

\author{
Lin Carver, Carol Todd, Karen Hahn, Keya Mukherjee \\ Saint Leo University, School of Education \& Social Services, Saint Leo, USA \\ Email: melinda.carver@saintleo.edu \\ Received May $18^{\text {th }}$, 2013; revised June $18^{\text {th }}$, 2013; accepted June $24^{\text {th }}$, 2013
}

\begin{abstract}
Copyright (C) 2013 Lin Carver et al. This is an open access article distributed under the Creative Commons Attribution License, which permits unrestricted use, distribution, and reproduction in any medium, provided the original work is properly cited.
\end{abstract}

\begin{abstract}
Online instruction is a growing field, but there are concerns about lack of student engagement with mastery of content. Researchers at a small, private, southern university were concerned about increasing student engagement with online course content. A synchronous interactive online tool (SIOT) was added to six sections of online graduate education courses. Data was collected and analyzed from the university administered end of the course survey questions asking students to rate their course learning. Student survey responses were compared from courses without a SIOT, courses where a SIOT was used for office hours, and courses where a SIOT was used for assignments. The differences in the question means from end of the course survey without the SIOT and those where the SIOT was used for office hours were not significant. However, when the SIOT was used to provide instruction related to student assignments, the data from the question responses were significantly more positive. Students 1) became more confident; 2) gained an excellent understanding of the concepts; 3) gained significant knowledge; 4) learned to analyze and critically evaluate; and 5) learned to apply course concepts to solve problems. Consequently it became evident that the implementation of the SIOT did not have a significant effect. The important component that impacted students' perception of their content understanding was the way in which the SIOT was used within the online course.
\end{abstract}

Keywords: Online Learning; Elluminate; Adult Learning; Content Mastery; Student Engagement; Graduate Education

\section{Introduction}

Online learning in the university environment is an ever expanding field. After examining the online enrollment at 2500 universities, Allen and Seaman (2006) found that during the 2004 fall semester, 2.3 million students took online courses. However, by 2008, that number had doubled to 4.6 million (Allen \& Seaman, 2010). Murray, Perez, Geist, and Hedrick (2012) suggested there would be continued growth in online learning. They predicted that by 2014 a majority of college students would be taking at least some of their courses online. Kester, Kirschner, and Corbalan (2006) found that the quality of interaction is an important component in the learning environment.

Adult learners identified ease of access and minimizing costs associated with courses as major advantages of online instruction (Ward, Peters, \& Shelley, 2010). Rising fuel prices and the economic recession have probably increased these concerns. However, adult learners also reported enjoying the convenience and opportunities online learning affords. Although these adult learners also expressed concerns about the quality of the instruction, learning, and interaction the online format provided (Ward, Peters, \& Shelley, 2010). Ward, Peters, and Shelley (2010) found that incorporating a Synchronous Interactive Online Instrument (SIOI) in an online course increased participant satisfaction with the online course.

\section{Purpose and Description of the Study}

The purpose of this study was to explore how flipping the typical online instruction to include opportunities for content interactions through a Synchronous Interactive Online Tool (SIOT), (adapted from the work of Ward, Peters, \& Shelley, 2010), impacted students' satisfaction with the online learning environment. Elluminate, an online conferencing tool was the SOIT used in the investigation by the researchers in this study. A mixed-method approach, was used to examine student satisfaction with graduate Educational Leadership, Exceptional Student Education, Reading, and Instructional Design courses from both the instructors' and the students' perspectives.

\section{Theoretical Framework and Review of Literature}

The literature review focused on three important areas for creating desirable learning environments: pedagogical orientation, the flipped classroom, and the role of immediacy and interaction in the learning process.

Typically, presenting relevant, complete, and accurate content is the major concern when constructing online courses (Murray et al., 2012). Murray et al.'s study examined the perceptions of 100 students enrolled in online courses. The students indicated they were not satisfied with online courses that 
used "flat resources, in the form of static text documents" (p. 126). Beard and Harper (2002) also identified student concerns based on the limited human interactions that are available in the online environment. This might be an important concern with graduate courses because they emphasize practitioner tasks that require students to transfer skills and integrate content knowledge into new situations. Particularly important to take into consideration for graduate students, were Schwartzman's (2007) findings that online learners often experience difficulty comprehending and applying information so just making the information available does not necessarily result in a successful educational course. Students need to know how to apply the information in new situations.

Students' perception of the characteristics of effective college instructors need also to be considered. Students viewed instructors as effective when they provided opportunities for multiple instructor and student interactions, they clearly and accurately conveyed information, and they effectively used time in the learning environment (Onweugbuzie et al., 2007). Respondents indicated that they felt instructors were effective when they were "student centered, expert, enthusiast, and ethical” (p. 151).

Goodwin and Miller (2013) examined preliminary data on the effectiveness of flipping classroom instruction so that lectures are recorded and posted online while instructional time is used for "homework" assignments. These online lectures included visual representations, graphics, videos, and photos which could be accessed by the student when they chose to use them, rather than spending instructional time on lecture materials. The original version of the graduate online courses contained lecture materials in a written format which were used as a basis for the materials students needed to know to create the homework assignments.

The researchers were interested in trying to flip the online instruction so that students receive additional scaffolding for the homework assignments. A Synchronous Interactive Online Tool, Elluminate, was incorporated to address the researchbased principles for effective instruction that teachers were attempting to incorporate into the flipped online classroom.

Sams and Bergmann (2013) indicated the importance of teachers responding to students' emotional and learning needs as well addressing their individual learning styles. Beesley and Apthrop (2010) found that feedback had a strong effect size (0.73). The researchers wanted to determine if the addition of a synchronous tool would provide opportunities for feedback and correcting misperceptions. The researchers chose a synchronous tool with recorded sessions to allow students to pace their own learning to match their individual needs. According to Hattie's (2008) meta-analysis of 800 research studies, he found that allowing students to pace their own learning had an effect size of .88. In addition, providing students opportunities to practice and apply skills with corrective teacher feedback was four times more effective than homework assignments alone (Beesley \& Apthrop, 2010). Consequently the researchers decided that the addition of a SIOI would address many of the teaching and learning strategies.

Hirumi (2002) found that interactions that increased content insights, provoked analysis, and deepened commitment result in higher academic achievement and engagement. He found that simply sharing personal observations; however, did not impact achievement. Students' performance and satisfaction increased with more collaboration between students and between students and instructors. Ho and Swan (2007) found that frequency, manner, and quality of contributions online were positively correlated to students' grades. However, Wanstreet (2006) found that research on online communication focused more on the quantity of the interactions as opposed to the quality of the interactions. So simply increasing the frequency of interactions did not positively impact students' achievement and engagement.

\section{Research Questions}

This study was conducted to determine if the addition of a SIOT would improve student and teacher satisfaction with online courses. Two research questions guided the study.

1) How will the addition of a SOIT impact students' perception of the effectiveness of their learning in an online course as measured by change in end of course evaluations?

2) Will the way the SIOT is used within the online course impact students' perception of their learning?

\section{Methodology}

Over the past two years at a small, private, southern liberal arts university, six graduate level courses taught by three different instructors were implemented in three ways: 1) totally online with no synchronous component; 2) online using a SIOT for office hours; and 3) online using a SIOT to provide practice for completing homework assignments in addition to the online component. At the completion of each course, the researchers collected and analyzed data from university administered student surveys. Student recorded their answer to the question using a Likert scale ranging from 1 to 5 . One corresponded with strongly disagree, while five corresponded to strongly agree. The section data from the questions relating to student learning in the six courses with the three different instructors were recorded and then the mean for each question was calculated. Data from three instructors were included in an attempt to correct for variability between instructors. The mean score for each question is recorded in Tables $\mathbf{1}$ and $\mathbf{2}$. A confidence interval of $95 \%$ was used to determine if the differences between the means were significant.

\section{Results}

The seven components of Student Perceptions of Learning section of the survey were analyzed using a paired t-test comparing the means of classes with no SIOT and classes where SIOT was used for office hours in addition to the online component. Results of the total student learning averages did not reveal a significant difference ( $p=0.173$ ) between students' perception of their learning in those classes where a SIOT was not used $(\mathrm{M}=3.920 ; \mathrm{SD}=0.27)$ and those classes where a SIOT was used for office hours $(\mathrm{M}=4.098$; $\mathrm{SD}=0.28)$. Although the means for the questions were higher with the SIOT being used for office hours, the difference between the means did not exceed the $95 \%$ confidence interval. The question asking students to evaluate their confidence related to the course content was the only question where the means were significantly different enough to reject the null hypothesis.

Next the data was analyzed to determine if the use of the SIOT to flip the class instruction was more effective than using it for office hours. The seven components of Student Perceptions of Learning were analyzed using a paired t-test comparing 
Table 1.

Student perception of learning without SIOT and using SIOT for office hours.

\begin{tabular}{|c|c|c|}
\hline \multicolumn{3}{|c|}{ Survey Question } \\
\hline No SIOT & SIOT Office Hrs. & $p^{*}$ \\
\hline \multicolumn{3}{|c|}{ Participated in each learning activity } \\
\hline 4.435 & 4.433 & 0.088 \\
\hline \multicolumn{3}{|c|}{ Became more confident } \\
\hline 3.809 & 4.341 & 0.012 \\
\hline \multicolumn{3}{|c|}{ Gained an excellent understanding of concepts } \\
\hline 3.642 & 3.808 & 0.452 \\
\hline \multicolumn{3}{|c|}{ Gained significant knowledge } \\
\hline 3.770 & 4.037 & 0.198 \\
\hline \multicolumn{3}{|c|}{ Learned something valuable } \\
\hline 4.207 & 4.058 & 0.541 \\
\hline \multicolumn{3}{|c|}{ Learned to analyze and critically evaluate } \\
\hline 3.760 & 3.942 & 0.510 \\
\hline \multicolumn{3}{|c|}{ Learned to apply course concepts to solve problems } \\
\hline 3.812 & 4.066 & 0.234 \\
\hline \multicolumn{3}{|c|}{ Total Student Learning Average } \\
\hline 3.920 & 4.098 & 0.173 \\
\hline
\end{tabular}

Note: ${ }^{*} p$ denotes probability.

Table 2.

Data on student perception of learning without SIOT and using SIOT for assignments.

\begin{tabular}{|c|c|c|}
\hline \multicolumn{3}{|c|}{ Survey Question } \\
\hline No SIOT & SIOT Assign. & $p^{*}$ \\
\hline \multicolumn{3}{|c|}{ Participated in each learning activity } \\
\hline 4.435 & 4.522 & 0.481 \\
\hline \multicolumn{3}{|c|}{ Became more confident } \\
\hline 3.809 & 4.315 & 0.007 \\
\hline \multicolumn{3}{|c|}{ Gained an excellent understanding of concepts } \\
\hline 3.642 & 4.243 & 0.005 \\
\hline \multicolumn{3}{|c|}{ Gained significant knowledge } \\
\hline 3.770 & 4.253 & 0.028 \\
\hline \multicolumn{3}{|c|}{ Learned something valuable } \\
\hline 4.207 & 4.335 & 0.655 \\
\hline \multicolumn{3}{|c|}{ Learned to analyze and critically evaluate } \\
\hline 3.760 & 4.272 & 0.026 \\
\hline \multicolumn{3}{|c|}{ Learned to apply course concepts to solve problems } \\
\hline 3.812 & 4.356 & 0.001 \\
\hline \multicolumn{3}{|c|}{ Total Student Learning Average } \\
\hline 3.920 & 4.319 & 0.007 \\
\hline
\end{tabular}

Note: ${ }^{*} p$ denotes probability. the mean of classes with no SIOT and classes where the SIOT was used for practice in completing homework assignments in addition to the online component. Results of the total student learning averages revealed a significant difference $(p=0.008)$ between those classes where SIOT was not used $(\mathrm{M}=3.920$; $\mathrm{SD}=0.27)$ and those classes where SIOT was used for practice in completing homework assignments $(\mathrm{M}=4.319$; $\mathrm{SD}=0.31)$. Student survey results from the individual questions related to student confidence, understanding of concepts, and applying concepts to solve problems were also significantly more positive with the use of the SIOT. The data from the survey questions related to student participation in all learning activities, academic value of the course, content based critical thinking, and knowledge growth did not reveal a statistically significant difference.

Using 95\% confidence interval six areas were found to be significant. These included students 1) became for confident; 2) gained an excellent understanding of the concepts; 3) gained significant knowledge; 4) learned to analyze and critically evaluate; and 5) learned to apply course concepts to solve problems.

\section{Discussion}

The only question where there was significant difference with both uses of the SIOT, either positive or negative, was students' response to their confidence with the course material. Interestingly, the mean scores for this question revealed approximately a half point of positive growth. This might be because in both uses of the SIOT, the students were able to get their specific issues clarified more easily. However, just the addition of the SIOT alone did not seem to significantly impact students' perception of their learning.

However, when the SIOT was used to expand content knowledge through practicing with assignments, the change in the students' perception of their learning was dramatic. Student means demonstrated about half a point of growth in five out of the seven categories. Data indicated significant differences in students' perception of gaining an excellent understanding of the course concepts, learning to apply course concepts to solve problems, and becoming more confident with the course content. Interestingly, the addition of the SIOT did not seem to impact students' perception of their participation in the course activities or their perception of the value of what they learned from the course. This might have been because these two categories were rated more highly in the initial surveys.

\section{Conclusion}

It is evident from the results of this study that the most important factor is how the SIOT is used within the course. Simply adding it to the course did not significantly impact students' perceptions as can be seen by the results from using the SIOT for office hours. When the SIOT was used to specifically support and expand content, students' perception of their learning increased. Often instructors are seen as a significant factor impacting student learning. However, the data indicated that even when the instructor variable was corrected, students' perception of their learning increased when the SIOT was used to add content and support assignments, no matter what instructor was teaching the course. Consequently, it would seem that students' perceived the synchronous component had a positive impact on 
their learning.

However, additional questions about the implementation of a SIOT in an online course still remain. This study was limited to graduate education students. It would be helpful to know if the findings can be generalized to a larger population in a variety of fields, such as business or medicine. A SIOT can be used in many different types of ways within an online course. These could include such activities as group work, videos, questions and answers, and presentations. It would be helpful to know which method of using students perceive is the most beneficial in increasing their understanding of the course content. These questions about the most effective use of the SIOT technology still need to be addressed.

\section{REFERENCES}

Allen, E., \& Seaman, J. (2010). Learning on demand: Online education in the United States, 2009. Needham, MA: Sloan-C.

Allen, E., \& Seaman, J. (2006). Making the grade: Online education in the United States, 2006. Needham, MA: Sloan-C.

Beard, L., \& Harper, C. (2002). Student perceptions of online versus on campus instruction. Education, 122, 658-663.

Beesley, A., \& Apthorp, H. (2010). Classroom instruction that works (2nd Ed). Denver, CO: McRel.

Goodman, B., \& Miller, K. (2013). Evidence on flipped classrooms is still coming in. Educational Leadership, 70, 78-80.

Hattie, J. (2008). Visible learning: A synthesis of over 800 metaanalyses related to achievement. New York: Routledge.
Hirumi, A. (2002). The design and sequencing of E-learning interactions: A grounded approach. International Journal on E-learning, 1, 19-27.

Ho, C., \& Swan, K. (2007). Evaluating online conversation in an asynchronous learning environment: An application of Grice's cooperative principle. The Internet and Higher Education, 10, 3-14. doi:10.1016/j.iheduc.2006.11.002

Kester, L., Kirschner, P., \& Corbalan, G. (2006). Designing support of facilitate learning in powerful electronic learning environments. Computers in Human Behavior, 23, 1047-1054.

Murray, M., Perez, J., Geist, D., \& Hedrick, A. (2012). Student interaction with online course content: Build it and they might come. Journal of Information Technology Education, 11, 125-140.

Onweugbuzie, A., Witcher, A., Collins, K., Filer, J. Wiednaier, C., \& Moore, C. (2007). Students' perceptions of characteristics of effective college teachers: A validity study of a teaching evaluation form using a mixed-method analysis. American Educational Research Journal, 44, 113-160. doi:10.3102/0002831206298169

Sams, A., \& Bergmann, J. (2013). Flip your students' learning. Educational Leadership, 7, 16-20.

Schwartzman, R. (2007). Electronifying oral communication: Refining the conceptual framework for online instruction. College Student Journal, 41, 37-49.

Wanstreet, C. (2006). Interaction in online learning environments: A review of the literature. The Quarterly Review of Distance Education, 7, 399-411.

Ward, M. E., Peters, G., \& Shelley, K. (2010). Student and faculty perceptions of the quality of online learning experiences. International Review of Research in Open and Distance Learning, 11, 57-77. 